\title{
Early postural blood pressure response and cause-specific mortality among middle-aged adults: what is the role of diastolic blood pressure?
}

\author{
Joep Lagro • Jurgen A. H. R. Claassen • \\ Marcel G. M. Olde Rikkert
}

Received: 26 April 2011 / Accepted: 23 June 2011/Published online: 28 August 2011

(C) The Author(s) 2011

Dear Editor,

With interest we have read the article by Fedorowski et al. [1], which provides valuable information about causespecific mortality in middle-aged subjects with orthostatic hypotension. In their study orthostatic hypotension (defined as a decrease in systolic blood pressure $\geq 20 \mathrm{mmHg}$ and/or decrease in diastolic blood pressure $\geq 10 \mathrm{mmHg}$ within 3 min of standing) was associated with mortality through injuries and neurologic diseases. Our major comment is that the article lacks data on the postural diastolic pressure response, both in describing the whole group with orthostatic hypotension, and the analyses of all cause and causespecific mortality.

Surprisingly, orthostatic hypotension and postural systolic blood pressure decline was not associated with cardiovascular mortality, although there was such an association in a smaller rescreened subsample. In other studies orthostatic hypotension was associated with myocardial infarction in middle-aged adults [2] and home dwelling elderly [3]. Unfortunately Fedorowski et al. [1] did not study the influence of postural diastolic blood pressure decline on cause-specific mortality. There might be a crucial role of diastolic blood flow on myocardial perfusion and subsequently myocardial infarction and cardiovascular mortality [3]. Postural diastolic, but not systolic blood pressure decline, seems to be associated with an increased risk of myocardial infarction [3]. Moreover in

J. Lagro ( $\square)$ · J. A. H. R. Claassen - M. G. M. Olde Rikkert Department of Geriatric Medicine, Radboud University Nijmegen Medical Centre, route 925, PO Box 9101, 6500 HB Nijmegen, The Netherlands

e-mail: j.lagro@ger.umcn.nl the same study population of the Malmö Preventive Project already the association was found that postural diastolic, but not systolic blood pressure decline predicts coronary events [4].

In conclusion, Fedorowski et al. [1] added very valuable information to the current knowledge of orthostatic hypotension through information on cause-specific mortality. However we miss in their study specific data on causespecific mortality in relation to postural diastolic blood pressure decline and especially regarding cardiovascular mortality.

\section{References}

1. Fedorowski A, Hedblad B, Melander O. Early postural blood pressure response and cause-specific mortality among middle-aged adults. Eur J Epidemiol 2011.

2. Rose KM, Tyroler HA, Nardo CJ, Arnett DK, Light $\mathrm{KC}$, Rosamond $\mathrm{W}$ et al. Orthostatic hypotension and the incidence of coronary heart disease: the Atherosclerosis Risk in Communities study. Am J Hypertens 2000; 13(6 Pt 1): 571-8.

3. Luukinen H, Koski K, Laippala P, Airaksinen KE. Orthostatic hypotension and the risk of myocardial infarction in the home-dwelling elderly. J Intern Med 2004; 255(4): 486-93.

4. Fedorowski A, Stavenow L, Hedblad B, Berglund G, Nilsson PM, Melander O. Orthostatic hypotension predicts all-cause mortality and coronary events in middle-aged individuals (The Malmo Preventive Project). Eur Heart J 2010; 31(1): 85-91. 
Table 1 Association between quartiles of diastolic blood pressure response ( $\Delta \mathrm{DBP})$, all-cause and cardiovascular mortality among 32,068 participants of the Malmö Preventive Project

\begin{tabular}{|c|c|c|c|c|}
\hline \multirow{2}{*}{$\begin{array}{l}\text { Causes of death } \\
\text { Hazard ratio }[95 \% \mathrm{CI}]\end{array}$} & \multicolumn{4}{|c|}{ Quartiles of $\Delta \mathrm{DBP}(\mathrm{mmHg})^{*}$} \\
\hline & $\begin{array}{l}\mathrm{Q} 11_{\mathrm{DBP}}^{\dagger} \\
+11.4 \pm 3.2 \\
\mathrm{n}=4,718 \\
(p \text { linear trend })\end{array}$ & $\begin{array}{l}\mathrm{Q} 2_{\mathrm{DBP}} \\
+5.0 \pm 0.1 \\
\mathrm{n}=8,768\end{array}$ & $\begin{array}{l}\mathrm{Q} 3_{\mathrm{DBP}} \\
0.0 \pm 0.0 \\
\mathrm{n}=14,207\end{array}$ & $\begin{array}{l}\mathrm{Q} 4_{\mathrm{DBP}} \\
-6.1 \pm 2.7 \\
\mathrm{n}=4,375\end{array}$ \\
\hline \multicolumn{5}{|l|}{ All causes } \\
\hline Model 1 & $\begin{array}{l}1.00 \\
<0.001\end{array}$ & $\begin{array}{l}1.06 \\
{[0.98-1.15]}\end{array}$ & $\begin{array}{l}1.07 \\
{[0.99-1.15]}\end{array}$ & $\begin{array}{l}1.20 \\
{[1.10-1.31]}\end{array}$ \\
\hline Model 2 & $\begin{array}{l}1.00 \\
0.13\end{array}$ & $\begin{array}{l}1.03 \\
{[0.96-1.12]}\end{array}$ & $\begin{array}{l}1.02 \\
{[0.95-1.10]}\end{array}$ & $\begin{array}{l}1.09 \\
{[1.00-1.19]}\end{array}$ \\
\hline \multicolumn{5}{|l|}{ CV disease only } \\
\hline Model 1 & $\begin{array}{l}1.00 \\
<0.001\end{array}$ & $\begin{array}{l}1.09 \\
{[0.98-1.22]}\end{array}$ & $\begin{array}{l}1.04 \\
{[0.93-1.16]}\end{array}$ & $\begin{array}{l}1.37 \\
{[1.23-1.53]}\end{array}$ \\
\hline Model 2 & $\begin{array}{l}1.00 \\
0.11\end{array}$ & $\begin{array}{l}0.97 \\
{[0.86-1.11]}\end{array}$ & $\begin{array}{l}1.00 \\
{[0.89-1.12]}\end{array}$ & $\begin{array}{l}1.12 \\
{[0.97-1.28]}\end{array}$ \\
\hline
\end{tabular}

* Mean \pm standard deviation; ${ }^{\dagger}$ reference quartile; Model 1 , adjusted for age and gender; Model 2, adjusted for age, gender, body-mass index, supine systolic blood pressure, antihypertensive treatment, diabetes, current smoking and total cholesterol

\section{The Authors' Reply}

Lagro and et al. commenting upon our article wonder why diastolic blood pressure response was not analyzed in this study. As a matter of fact, we did perform and include these analyses in the initial version of the submitted manuscript. However, as the association between postural diastolic change and cause-specific mortality (including cardiovascular death) did not substantially differ from that for systolic change, and thus did not alter our conclusions, we were advised to omit these results. As can be seen in Table 1, $\triangle \mathrm{DBP}$ wasn't a better predictor of cardiovascular (CV) death than $\triangle \mathrm{SBP}$.

In our previous article cited by Lagro and et al. [1], we observed that younger individuals $(<42$ years $)$ with orthostatic hypotension $(\mathrm{OH})$ had higher mortality than older ones ( $>48$ years) but the latter had in contrast higher risk of incident coronary event. It would explain why in the rescreened (and naturally older) subset of MPP a significant association between $\mathrm{CV}$ death and $\mathrm{OH}$ or hypotensive SBP response was found. Probably, the reduced time to CV event among older adults accentuates the relationship between prevalent orthostatic impairment and progression of $\mathrm{CV}$ disease, whereas among younger individuals other concomitant $\mathrm{CV}$ risk factors (such as smoking, hypertension or diabetes) have a more prominent role. Moreover, in the rescreened subset of MPP, orthostatic hypotension defined as SBP drop $\geq 20 \mathrm{mmHg}$ alone was the best predictor of mortality and CV events [2]. Thus, we believe that the role of $\mathrm{OH}$ as a $\mathrm{CV}$ risk factor increases with advancing age, and that $\triangle \mathrm{SBP}$ alone may be used as a reliable marker of postural haemodynamic homeostasis.

Open Access This article is distributed under the terms of the Creative Commons Attribution Noncommercial License which permits any noncommercial use, distribution, and reproduction in any medium, provided the original author(s) and source are credited.

\section{References}

1. Fedorowski A, Stavenow L, Hedblad B, Berglund G, Nilsson PM, Melander O. Orthostatic hypotension predicts all-cause mortality and coronary events in middle-aged individuals (The Malmo Preventive Project). Eur Heart J 2010;31:85-91.

2. Fedorowski A, Stavenow L, Hedblad B, Berglund G, Nilsson PM, Melander O. Consequences of orthostatic blood pressure variability in middle-aged men (The Malmo Preventive Project). Journal of hypertension 2010;28:551-559.

Artur Fedorowski

Olle Melander

Center for Emergency Medicine, Skåne University Hospital,

Entrance 35, Floor 2, 20502 Malmö, Sweden 